\section{Sustainability is key to development goals}

As the United Nations General Assembly meets in New York this week, the global community should look beyond the 2015 expiry of the Millennium Development Goals (MDGs). We need to embrace environmental sustainability to alleviate poverty, and to ensure that economic growth does not generate inequality. Development challenges must be addressed worldwide, going beyond the traditional divides of north versus south, or rich versus poor.

The MDGs on global poverty, health, education and gender equality have provided an unprecedented rallying point for action by governments, civil society, international agencies and the private sector. The numbers of people without access to safe drinking water, living in extreme poverty and dying during childbirth have all been halved since 1990. But what comes next is urgent.

We have to tackle the new interlocking realities: inequality is worsening in many areas; 1.3 billion people still live on less than US $\$ 1.25$ per day; pressure on natural resources is growing; and climate change is upon us. The world is changing profoundly as the middle class expands globally, and more people now live in cities than in rural areas.

New ideas, including the push for Sustainable Development Goals, are emerging that could help to shift the development agenda in the right direction. Manish Bapna World Resources Institute, Washington DC, USA. mbapna@wri.org

\section{Arab science must help itself}

Ehsan Masood urges Arab liberals to help to build Islamic science policy (Nature 488, 131; 2012). Regrettably, academics who participated in the Arab Spring are still constrained by opposing military, religious or even tribal forces.

There are other ways to strengthen scientific progress. These would include increasing national investment in local human resources and boosting support from international stakeholders for developing science and technology.

The Middle East and North Africa must also discard their long history of 'selfloathing, which manifests as deference to Western expertise, undervaluation of distinguished expatriates and resistance to their advice. On my travels around the region, I hear from internationally renowned Arab experts who have tried to offer assistance to local establishments, only to be rebuffed or treated as second class.

The region must convince scientists in the diaspora that it is serious about promoting its own science and education. Most important, it must embrace diversity and freedom of thought. Mustafa al'Absi University of Minnesota Medical School, Duluth, Minnesota, USA. malabsi@umn.edu

\section{Preprint servers: no author fees}

Prepublication of scientific papers on preprint servers such as arXiv.org allows prompt scrutiny of the research by the scientific community (see, for example, go.nature.com/ nwjmbt). Because the results are freely accessible, the arXiv approach is infinitely superior to the 'author pays' model of open-access journal publishing that is being pushed as a way to penetrate the paywall.

The number of mathematics and physics papers being posted to arXiv is rapidly increasing; subsequent publication in a journal serves mainly to validate the results.

Making authors pay to publish their research endangers the open and egalitarian nature of the scientific enterprise. Researchers in developing countries, unaffiliated researchers, graduate students and faculty members without large federal grants could all be priced out of publishing their work. The arXiv model offers a sensible and affordable alternative.

Ilya Kapovich University of Illinois at Urbana-Champaign, Urbana, Illinois, USA.

kapovich@math.uiuc.edu

\section{Preprint servers: follow arXiv's lead}

In the spirited debate on openaccess publishing (see, for example, Nature 487, 302; 2012), it is worth remembering that the process is likely to be different in different research fields.

Self-archiving of pre- and postprint versions of research papers in high-energy physics on the arXiv.org server (the 'green' model of open-access publishing) has been running smoothly since 1991. In this model, the peer-review system of the scientific journals serves as a quality stamp. The system works because of institutional subscriptions to journals.

I would encourage scientists in other fields take a closer look at the arXiv model.

Tommy Ohlsson $K T H$ Royal Institute of Technology, Stockholm, Sweden.

tohlsson@kth.se

\section{Realizing Australia's bioenergy potential}

Andrew Lang and his colleagues present an enthusiastic vision for bioenergy in Australia (Nature 488, 590-591; 2012). However, the country's large area and low population notwithstanding, the contribution of biomass to the national renewable-energy portfolio will be constrained by poor soils, low primary productivity and the time and logistics needed to establish plantings.
Optimistic projections of bioenergy production and usage based on biomass flows and operation costs in other countries can harm the industry by unrealistically raising public expectations. Australia's sustainable biomass production might be enough to replace $15 \%$ of electricity demand or $34 \%$ of current petroleum consumption (D. R. Farine et al. GCB Bioenergy 4, 148-175; 2012). Investors and decisionmakers will need to make real-world tests of assumptions and uncertainties in their own national and local contexts.

Advanced energy-generation technologies based on woody lignocellulose sources are reducing the impact of the bioenergy sector on food crops, but more research, development and investment are needed to find sustainable ways of resolving the competition for land and water.

Realizing Australia's bioenergy potential will take time.

Supportive policies are needed to reduce the risk for investment. Regional hotspots for economic and sustainable bioenergy production must be identified and technology locally matched to biomass resources and scale of use. A clear strategy will be needed to incorporate biomass resources effectively into the suite of available renewable energies.

Luis C. Rodriguez, Alexander Herr, Michael H. O'Connor CSIRO Ecosystem Sciences, Australia.

luis.rodriguez@csiro.au

\section{CORRECTION}

The Outlook article 'Trials of an anticancer jab' (Nature 488, S4-S6; 2012) contained an error in the table: in Australia, the uptake for at least 1 dose is $83 \%$ not $74 \%$. The label in the graphic stated that vaccination started in 2010 instead of 2007. And reference 9 should have read Tabrizi, S. N. et al. J. Infect. Dis. (in the press). 